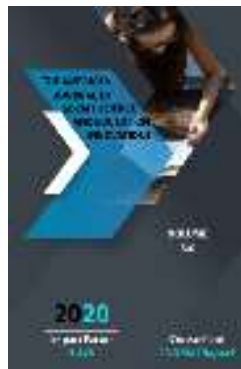

\title{
Conflicts In Approaches To Cognitive And Conceptual Metaphorical Classification
}

\section{Sh.T. Makhmaraimova}

Associate Professor, Termiz State University, Termiz, Uzbekistan

Journal Website: http://usajournalshub.c om/index,php/tajssei

Copyright: Original content from this work may be used under the terms of the creative commons attributes 4.0 licence.

\section{ABSTRACT}

The article provides a scientific commentary on the phenomena of cognitive and conceptual metaphors, as well as a response to existing theories in world linguistics. The different aspects of cognitive and conceptual metaphors are also revealed, with particular emphasis on J. Lakoff's classifications in this regard.

\section{KEYWORDS}

Cognitive metaphor, conceptual metaphor, existing linguocognitive approaches in world metaphorology.

\section{INTRODUCTION}

The terms "cognitive metaphor" and "conceptual metaphor" have been widely used since the 1980 s based on J. Lakoff's views on the cognitive paradigm. The debate between these two terms is, in fact, a correct interpretation of the phenomenon of "cognitive metaphor" and "conceptual metaphor" that were in scientific use between 1960 and 1980, which was recognized in world linguistics as the "first stage of cognitive linguistics" was the result of ignorance. Consequently, at this time, the scientific ideas of the American school of linguistics on cognitive semantics were beyond the scope of N. Khomsky's structural linguistics, in world linguistics the progressive influence of the cognitive sciences was gradually beginning to be observed. 


\section{LITERATURE REVIEW}

According to T.G. Skrebsova, since the second half of the twentieth century, Russian linguists have misinterpreted both types of metaphors due to a misunderstanding of the essence and linguistic nature of "cognitive metaphors" and "conceptual metaphors" [Skrebsova, 2011:4]. However, it should be noted that in Russia in the 1970 s and 1980 s and in the 1990s there was a lot of fundamental research on cognitive metaphors. [Arutyunova, 1978; Baranov, 2008; Budayev, 2008; Buynova, 2001; Kimov, 2010; Oparina, 1988; Skrebsova, 2011; Telia, 1988]. The study of these two periods does not affect the theoretical foundations of different schools of cognitive linguistics (the sources emphasize the research of Berkeley and San Diego linguists from California, which contributed to the development of cognitive linguistics) [Johnson, 1997; Lakoff, 1993; Kulchitskaya, 2012]) of course. According to A.P.Chudinov, traditional approaches to the cognitive and conceptual metaphors did not completely abandon the traditional views of the Aristotle period, rather, he began to interpret cognitive and conceptual metaphors based on his best ideas [Chudinov, 2013]. However, it was not until the 1990s that significant research into the differences between the terms "cognition" and "conceptualization" began to emerge. By this time, scientists had begun to examine the "cognitive" and "conceptual" properties in a truly distinctive way. Consequently, cognitive metaphor, as J. Lakoff points out, is a cognitive tool for understanding the ideal phenomenon, abstract concepts, and abstract ways of thinking ("metaphor is a cognitive tool we use to comprehend abstract concepts and perform abstract reasoning"), the leading mechanism of perception of one event (with similar properties - M.Sh.) through the second event "The cognitive mechanism for such conceptualizations is conceptual metaphor") as "all the time and everywhere" (ubiquity, (all) omnipresence) reflects the principle that the behavior of the speaker of the language is finally reflected in the language and speech, interfering with the way of thinking [Lakoff, 1993: 51].

\section{THE MAIN RESULTS AND FINDINGS}

Distinguishing between conceptual and cognitive metaphors, J. Lakoff relies on their characteristics, which reflect the characteristics of the neural or conceptual level of brain activity ("reality either at the neural or conceptual level"). According to the scientists, if a conceptual metaphor reflects mental projections between the source and target conceptual areas ("crossdomain mappings from a source domain to a target domain"), it is expedient to interpret the cognitive metaphor as a mechanism of neurophysiological activity related to the processes at the level of neuronal activation [Lakoff, 1999:58]. In other words, while conceptual metaphor is the process by which human thinking goes through concepts, reflections, and conclusions, cognitive metaphor represents the neurophysiological substrate of the brain. (Table 3 ). 
Table 3

\begin{tabular}{|c|c|c|c|}
\hline $\begin{array}{l}\text { Type of } \\
\text { metaphor }\end{array}$ & Signs & Feature & Locus \\
\hline $\begin{array}{l}\text { Conseptual } \\
\text { metaphor }\end{array}$ & $\begin{array}{l}\text { represents mental } \\
\text { projections between the } \\
\text { source and target } \\
\text { conceptual areas }\end{array}$ & $\begin{array}{l}\text { represents the } \\
\text { process by which } \\
\text { human thought goes } \\
\text { through concepts, } \\
\text { reflections, and } \\
\text { conclusions }\end{array}$ & $\begin{array}{l}\text { mental } \\
\text { activity, } \\
\text { conceptua } \\
\text { I process in } \\
\text { thinking }\end{array}$ \\
\hline $\begin{array}{l}\text { Congitive } \\
\text { metaphor }\end{array}$ & $\begin{array}{l}\text { neurophysiological } \\
\text { activity is interpreted as a } \\
\text { mechanism associated } \\
\text { with processes at the level } \\
\text { of neuronal activation }\end{array}$ & $\begin{array}{l}\text { expresses the } \\
\text { neurophysiological } \\
\text { substrate of the brain, } \\
\text { discovering new } \\
\text { meanings }\end{array}$ & $\begin{array}{l}\text { the } \\
\text { neurophysiologic } \\
\text { al substrate of } \\
\text { the brain }\end{array}$ \\
\hline
\end{tabular}

Table 3. Differences between conceptual and cognitive metaphors (according to J.

\section{Lakoff, American and Russian linguists)}

Cognitive metaphor is another famous linguist N.D. Arutyunov has a functional: the nominative case (transfer of meaning: in this case, a metaphor is a means of discovering a new meaning that is absent in the language), figurative (transition of descriptive meaning to predicate meaning), interpreted as a generating type [Arutyunova, 1978: 333-343]. Among these, the generalizing metaphor is interpreted as the final stage of the formation of the cognitive metaphor. The scholar examines the metaphor in place of the outdated but filled with new meaning. The separation of the characters belonging to the two simulated objects, in turn, determines the entry of the words representing these characters into the prediction process; which leads to metaphorical migration and, through it, polysemy [Arutyunova, 1978: 340]. N.D. Arutyunova also observes the cognitive metaphor mainly in predicate words that create new meaning, in which three: 1) metaphorical movement of predicate words in sign words; 2) the emergence of new meanings and concepts based on the transfer of metaphorical meaning; 3) recognizes goals as 
an important tool of cognition (epistemology) and considers the predicate metaphor to be important in the formation of vocabulary that represents the characteristics of reality in the invisible worlds [Arutyunova, 1978: 336].

V.N. Telia, like N. D . Arutyunova, describes the cognitive metaphor as a speech metaphor. Comparing the types of metaphors, the scholar, based on the functions performed by the metaphor, adds: identifies (identifies, equates) , in other words, indicative, predicative, evaluative, emotional (evaluativeexpressive) and figurative metaphors [Kulchitskaya, 2012: 85-90; Telia, 1988: 193, 173204]. V.N. Telia notes that the metaphor serves to name the physical and abstract objects of the two sexes: visual (perceived through experience, showing real similarity) and perceived by the mind. Of course, the similarities between the objects of real events are easy to see: it is easy to distinguish them by comparing and contrasting their different characters. Therefore, metaphors in this category are called identifying (indicative) metaphors.

Metaphorical models representing invisible worlds have a hypothetical-cognitive modality "if the object $X$ has the characteristics of the object Y" [Kulchitskaya, 2012: 85-90; Telia, 1988: 193, 173-204]. The same alternative allows us to distinguish between the probable common denominator between the machine and human memory on the basis of the "if the machine had a human brain" model [Kulchitskaya, 2012: 85-90; Telia, 1988: 193, 173204]. Also, the metaphorical classification given to non-subject objects makes it possible that new (abstract) meanings will emerge in the future. Because of this, V.N. Telia calls these metaphors cognitive metaphors. Thus, the indicative metaphor is "not a cognitive process, but a product of linguocreative techniques in human empirical activity".[ Telia, 1988: 193, 173-204]. In other words, V.N. Telia does not accept indicative metaphor as a cognitive metaphor. In contrast, J. Lakoff and M. Johnson present the metaphor of language as a product of the cognitive activity of the metaphorical mechanism in brain devices. V.N. Telia summarizes his views based on the views of these two linguists. That is, the scientist divides the metaphor into identifiable, cognitive, and figurative metaphors. However, an evaluative-expressive metaphor is formed on the basis of a new concept that arises as a result of the task of identifying the metaphor or cognitive description of reality [Telia, 1988: 193, 173-204]. There is an incomprehensible aspect in this classification of V.N. Telia: metaphors such as "computer memory" are among the cognitive metaphors that the scientist forms abstract concepts, Metaphors such as the "knee cap" are called indicative. In our opinion, both types of metaphors, classified as indicative and cognitive, are the product of a single mechanism that allows to know, understand, classify, differentiate at the same time and evaluating it as separate derived types of metaphor is tantamount to misinterpreting the true cognitive nature of the metaphor. Furthermore, there is some irrationality in focusing only on the material and intangible aspects of the objects that metaphor names, and on this basis dividing them into identifying, cognitive and figurative types of metaphor. Consequently, the basis of the metaphor for naming an intangible object is not empty, but rather a set of re-arranged knowledge about the same object that is considered abstract because of the metaphor. This knowledge also includes interdisciplinary 
taxonomic features. And in this case, the differences between objects and concepts are revealed through the metaphorical activity of thought. Thus, it is incorrect to divide metaphors into cognitive, identifiable types, relying only on the naming of a specific and abstract object by a particular metaphorical nominative as a speech product. Each metaphorical nomination represents the result of the process of knowing, understanding, and, accordingly, the stage of conclusion [Makhmaraimova,]. Thus, cognition is one of the functions of metaphor, the separation, observation and evaluation of different signs between subjects are also specific functions in its structure, and so on. So let's take the word landscape. The word can be approached simultaneously with terms such as lexeme, morpheme, concept, product of cognitive activity, and so on. Because all these qualities are reflected in the landscape. Cognitive stages that reflect these qualities, occur in sequence, and condition each other play an important role in the placement of the word landscape as a separate meaning / concept in the human cognitive world. The metaphor is the same: it is the product of the activity of a unique phenomenon of human thought. Its cognitive nature can be studied in terms of small qualities, but it is wrong to study the speech expressions he creates into completely different types of metaphors based on these qualities. Personally, in O.Y. Buynova's scientific hypotheses, we see a more precise definition of metaphor. The scholar imagines metaphor in language and in the universe in general [Buynova, 2001: 49-65]. The metaphor of the universe (conceptual metaphor) is a phenomenon that creates new concepts and images. What is pleasing to us in this view is that the metaphor in the universe is a proof of the linguistic, intellectual competence of the human mind, and the metaphor in language is the expression of this ability in speech. But we do not agree with O.Y. Buynova's acceptance of cognitive and conceptual metaphors as mutually synonymous [Buynova, 2001: 49-65].

Elsewhere, V.N. Telia distinguishes indicative, conceptual, evaluative, and emotional metaphors as functional types of metaphors [Telia, 1988:26-52, 42]. The scholar, who combines conceptual and cognitive metaphors in her views, interprets them as functionally oriented metaphors that form new concepts of intangible reality [Telia, 1988: 193]. However, in her imagination, the scientist evaluates the cognitive metaphor at the level of the element that names the scientific phenomena, and thus raises it (cognitive metaphor to a new level). According to her, the nature of the metaphor that creates new meaning is studied as a problem of verbalization of conceptual content in the context of philosophical problems. [Telia, 1988:170-172]. In general, in the works of VN Telia, it can be seen that the term "conceptual" was gradually replaced by the term "cognitive", which led to the emergence of the concept of cognitiveconceptual.

\section{CONCLUSION}

It is clear that for many years in world linguistics there has been a process of not dividing cognitive and conceptual metaphors in their classification, but studying them as mutually synonymous terms. True, metaphor is anthropocentric in itself, and it is, of course, a clear indication of the anthropocentric nature of language. However, a holistic view of the universe is not formed in the early stages of human cognition. As a result, human cognitive activity is constantly reviewing the knowledge 
generated in the process of learning, conclusions can be changed over time, and some can be abandoned. However, it is appropriate to consider conceptualization as one of the final stages of the cognitive process, and the only idea (conclusion) about the universe is determined by the process of cognition that accompanies humanity throughout its life.

\section{REFERENCES}

1. Arutyunova N.D. Functional types of language metaphor // Izvestiya AN SSSR. Ser. Literature and linguistics. 1978 .-- T. 37. - № 4. - P. 333-343;

2. Baranov A. N., Dobrovolskiy D. O. Aspects of the theory of phraseology. Moscow:. Sign, 2008;

3. Budaev E.V., Chudinov A.P. Metaphor in political communication: monograph. - Moscow:. Science, 2008;

4. Buinova O.Y. Universal and specific features of the metaphorization process // Linguistic research. To the 75th anniversary of Professor V.G. Gak. Dubna: Phoenix +, 2001. - P. 49-65;

5. Kimov R.S. Metaphor and metonymy as cognitive and epistemic mechanisms for the formation of a linguistic picture of the world. - Nalchik: Cab.-Balk. un-t, 2010;

6. Kulchitskaya L.V. The concepts of "cognitive" and "conceptual" metaphor in Russian linguistics of the early cognitive period // Bulletin of the Buryat State University 11/2012. - P. 85-90.

7. Oparina E.O. Conceptual metaphor // Metaphor in language and text. Moscow:. Science, 1988. - P. 65-78;
8. Skrebtsova T.G. Cognitive linguistics: a course of lectures. - SPb:. Filol. Faculty of St. Petersburg State University, 2011. - P. 4.

9. Telia V.N. Metaphor as a model of meaning production and its expressiveevaluative function // Metaphor in language and text. - Moscow:.Science, 1988. - P. 26-52;

10. Telia V.N. Afterword // Metaphor in language and text. - Moscow:. Science,1988. - P. 170-172. - P. 170.

11. Telia V.N. Metaphorization and its role in creating a linguistic picture of the world // The role of the human factor in language: Language and linguistic picture of the world. - Moscow:. Science, 1988. - P. 193, 173-204.

12. Chudinov A.P. Ch. Essays on modern political metaphorology: Monograph / Ural. state ped. un-t. - Ekaterinburg, 2013.

13. Johnson M. The Body in the Mind: The bodily Basis of Meaning, Reason and Imagination. - Chicago: Chicago University Press, 1997. - 272 p.;

14. Lakoff G. The Contemporary Theory of Metaphor // Metaphor and Thought, edited by Andrew Ortony. - Cambridge: Cambridge University Press, 1993. - Pp. 244. 202-51.

15. Lakoff G., Johnson M. Philosophy in the Flesh: The Embodied Mind and Its Challenge to Western Thought. / G. Lakoff, M. Johnson. - New York, NY: Basic Books, 1999. - P. 58.

16. Makhmaraimova Sh. The Role of Metaphoric and Empirical Knowledge in the Process of Cognition / International Journal of Psychosocial 
Rehabilitation, Vol. 24, Issue 01, 2020. P. 218-222.

17. Makhmaraimova Sh. Approximation a metaphorical interpretation in the nomenclature representing a vague / precise category/ International Scientific Journal Theoretical \& Applied Science. Published: 08.08.2019. Issue: 08 Volume: 76. P. 53-56.

18. Makhmaraimova Sh. The linguoculturological features of theomorphistic metaphor of peri / IMPACT: International Jurnal of Research in Humanities, Arts and Leteratura. (IMPACT: IJRHAL) Vol. 4, Issue 2, Feb. 2016. (№ 2 Index Copernicus Impact Factor - 1,7843) -P. 35-40.

19. Makhmaraimova Sh. The linguoculturological features of theomorphistic metaphor of peri //International Journal of Anglisticum. Literature, Linguistics and Interdisciplinary Studies. Volume:7, Issue:91 - Macedonia:, 2018. - P. 90-96 (CV Impact factor -6,88).

20. Kurbonazarova, N. S. (2020). The Linguocultural Aspect Of Ethnographic Units In The Linguistic System (The Example Of Wedding Ceremonies In Surkhandarya). The American Journal of Social Science and Education Innovations, 2(10), 259-263.

21. Kurbonazarova, N. (2019). A REVIEW OF SOME WEDDING CUSTOMS IN THE SURKHANDARYA AREA. Theoretical \& Applied Science, (12), 405-410. 